\title{
Inhibitory Effect of Flower-Shaped Zinc Oxide Nanostructures on the Growth and Aflatoxin Production of a Highly Toxigenic Strain of Aspergillus flavus Link
}

\author{
David Hernández-Meléndez ${ }^{1}$, Enrique Salas-Téllez ${ }^{2}$, Anai Zavala-Franco ${ }^{3}$, Guillermo Téllez ${ }^{4}$, \\ Abraham Méndez-Albores $1, *$ (iD and Alma Vázquez-Durán ${ }^{1, *}$ \\ 1 UNAM-FESC, Campus 4, Multidisciplinary Research Unit L14-Annex 1 (Materials Science and Technology), \\ Cuautitlan Izcalli 54714, Mexico; david.hm.bqd@gmail.com \\ 2 UNAM-FESC, Campus 4, Multidisciplinary Research Unit L17 (Microbiology and Mycology), \\ Cuautitlan Izcalli 54714, Mexico; satenrique@gmail.com \\ 3 Center for Research and Advanced Studies of the National Polytechnic Institute (CINVESTAV-IPN), \\ Libramiento Norponiente 2000, Fraccionamiento Real de Juriquilla, Queretaro 76230, Mexico; \\ anai.zavala@cinvestav.mx \\ 4 Department of Poultry Science, University of Arkansas, Fayetteville, AR 72701, USA; gtellez@uark.edu \\ * Correspondence: albores@unam.mx (A.M.-A.); almavazquez@comunidad.unam.mx (A.V.-D.); \\ Tel.: +52-55-5623-1999 (ext. 39409) (A.V.-D.)
}

Received: 19 June 2018; Accepted: 19 July 2018; Published: 24 July 2018

\begin{abstract}
Flower-shaped zinc oxide $(\mathrm{ZnO})$ nanostructures were prepared via a simple aqueous precipitation strategy at room temperature. The as-grown nanostructures were characterized by UV-vis spectroscopy, UV-vis diffuse reflectance spectroscopy (DRS), spectrofluorometry, Fourier transform infrared (FTIR) spectroscopy with attenuated total reflection (ATR), X-ray diffraction (XRD), and field emission scanning electron microscopy (FESEM). The antifungal and anti-aflatoxigenic activities of the $\mathrm{ZnO}$ nanostructures were further investigated using a highly toxigenic strain of Aspergillus flavus Link under in vitro and in situ conditions. The results showed that the A. flavus isolate was inhibited to various extents by different concentrations of $\mathrm{ZnO}$ nanostructures, but the best inhibitions occurred at 1.25, 2.5, and $5 \mathrm{mM}$ in the culture media. At these concentrations, suppression of aflatoxin biosynthesis $(99.7 \%)$ was also observed. Moreover, a reasonable reduction in the aflatoxin content (69\%) was observed in maize grains treated with the lowest $\mathrm{ZnO}$ concentration that exhibited the strongest inhibitory activity in the liquid media. SEM micrographs clearly indicate multiple degenerative alterations in fungal morphology after treatment with $\mathrm{ZnO}$ such as damage of the tubular filaments, loss of hyphae shape, as well as hyphae rupture. These results suggest that flower-shaped $\mathrm{ZnO}$ nanostructures exhibit strong antifungal and anti-aflatoxigenic activity with potential applications in the agro-food system.
\end{abstract}

Keywords: ZnO nanostructures; Aspergillus flavus; antifungal; anti-aflatoxigenic activity

\section{Introduction}

Transition metal-based oxides are among the most produced nanomaterials due to their multipurpose applications in chemistry, biology, medicine, biotechnology, molecular engineering, and physics. In recent times, dimensional nanostructured materials have attracted special attention; for that reason, considerable effort has been made to develop controlled synthesis protocols, since the properties and potential applications depend on their shape and size [1]. Zinc oxide $(\mathrm{ZnO})$ is an 
important multifunctional, intrinsic II-VI semiconductor material, with a wide band gap $(3.37 \mathrm{eV})$, large exciton binding energy $(60 \mathrm{meV})$, high transmission coefficient, high chemical stability, and low threshold intensity [2,3]. Being an n-type semiconductor, the electron mobility in $\mathrm{ZnO}$ nanomaterials is enhanced [4]. ZnO (21 CFR 182.8991) is considered as a GRAS (generally recognize as a safe) substance by the United States Food and Drug Administration. At present, with the development of material science, it is expected that $\mathrm{ZnO}$ has further applications in many aspects of food and agriculture.

Mexico, with an estimated population of 124.7 million people, has the highest world per capita consumption of maize. In 2017, national maize production was 21.5 million metric tons [5]. Regrettably, maize is contaminated by certain fungal species, among them Aspergillus flavus Link. The toxins synthesized by $A$. flavus are named aflatoxins (AF), and include four major structures: $\mathrm{AFB}_{1}, \mathrm{AFB}_{2}$, $\mathrm{AFG}_{1}$, and $\mathrm{AFG}_{2}[6]$. Aflatoxins represent a public health problem, since toxins could be synthesized both in the field as well as in the storage [7]. $\mathrm{AFB}_{1}$ has strong carcinogenicity potential; consequently, it has been classified by the International Agency for Research on Cancer as a human carcinogen, Group 1 [8].

The best approach to control aflatoxin contamination in maize is to prevent aflatoxin formation. In the field, the aflatoxin production threat can be diminished by the use of some agricultural practices that limit the establishment of the fungus on the maize cob [9]. In the postharvest system, an appropriate drying process can mitigate the aflatoxin formation during grain storage; however, developing countries lack access to postharvest technology. Moreover, fungi can be controlled by organic synthetic fungicide application, but their control is difficult, due to resistance to many traditional antifungal agents such as benzimidazoles, demethylation inhibitors, Qo respiration inhibitors, and dicarboximides [10]. To overcome this situation, it is imperative to explore other alternatives. Although antifungal activity of $\mathrm{ZnO}$ nanoparticles has been widely studied, just few articles have been published on their antifungal and anti-aflatoxigenic activity against $A$. flavus Link [11-14]. However, no attempt has yet been made to evaluate the inhibitory effect of nanostructured $\mathrm{ZnO}$ against a highly toxigenic strain of $A$. flavus. Therefore, the objectives of the present research were to synthesize and characterize flower-shaped $\mathrm{ZnO}$ nanostructures, and evaluate their antifungal and anti-aflatoxigenic effectiveness against a highly toxigenic strain of A. flavus Link in liquid media and on maize grains.

\section{Materials and Methods}

\subsection{Safety Measures in Laboratory}

Sodium hypochlorite $6 \%(w / v)$ was used to surface-disinfect equipment and working areas. Wastes containing fungal spores and mycotoxins were first steam sterilized and then immersed in the sodium hypochlorite solution overnight.

\subsection{Chemical Compounds}

Zinc nitrate hexahydrate $\left(\mathrm{Zn}\left(\mathrm{NO}_{3}\right)_{2} \cdot 6 \mathrm{H}_{2} \mathrm{O} ; 98 \%\right.$ purity; CAS number 10196-18-6), potassium hydroxide (KOH; $90 \%$ purity; CAS number $1310-58-3)$, glutaraldehyde solution $\left(\mathrm{OHC}\left(\mathrm{CH}_{2}\right)_{3} \mathrm{CHO}\right.$; $50 \%$ in $\mathrm{H}_{2} \mathrm{O}$; CAS number 111-30-8), tween-80 (CAS number 9005-65-6), methanol $\left(\mathrm{CH}_{3} \mathrm{OH}, \mathrm{CAS}\right.$ number 67-56-1), methanol HPLC grade $\left(\mathrm{CH}_{3} \mathrm{OH}, \mathrm{CAS}\right.$ number $\left.67-56-1\right)$, sodium chloride ( $\mathrm{NaCl}, \mathrm{CAS}$ number 7647-14-5), and Sabouraud dextrose broth (SDB) were obtained from Merck KGaA (Darmstadt, Germany). Dehydrated culture media: potato dextrose agar (PDA) was procured from BD Bioxon (Becton Dickinson de Mexico SA de CV, Estado de Mexico, Mexico). Bromine solution (0.03\%) was purchased from Vicam (Milford, MA, USA). All solutions were prepared using deionized water.

\subsection{Synthesis and Characterization of $\mathrm{ZnO}$ Nanostructures}

Flower-shaped $\mathrm{ZnO}$ nanostructures were engineered at room temperature as follows: $100 \mathrm{~mL}$ aqueous solution of $\mathrm{Zn}\left(\mathrm{NO}_{3}\right)_{2} \cdot 6 \mathrm{H}_{2} \mathrm{O}(0.4 \mathrm{M})$ was vigorously stirred for $20 \mathrm{~min}$ in a $250 \mathrm{~mL}$ flat bottom 
flask. Afterwards, $\mathrm{KOH}(2 \mathrm{M})$ solution was added to the zinc solution to rise the $\mathrm{pH}$ value to 12 . After completion of the reaction $(2 \mathrm{~h})$, the resultant suspension was aged for $12 \mathrm{~h}$. The white suspension was centrifuged $(3200 \times g, 5 \mathrm{~min})$, and the precipitate was exhaustively washed with deionized water to remove the byproducts. Finally, the sample was oven dried at $120^{\circ} \mathrm{C}$ for $2 \mathrm{~h}$ and annealed at $600{ }^{\circ} \mathrm{C}$ for $1 \mathrm{~h}$, in air atmosphere.

$\mathrm{ZnO}$ nanostructures were further characterized by UV-vis absorption (Agilent Technologies, Santa Clara, CA, USA), diffuse reflectance spectroscopy (DRS, Perkin Elmer, Waltham, MA, USA), fluorescence (Perkin Elmer, Waltham, MA, USA), and Fourier transform infrared spectroscopy with attenuated total reflection (FTIR-ATR, Perkin Elmer, Waltham, MA, USA) according to the methodologies proposed by Estrada-Urbina et al. [15]. The X-ray measurements were recorded with a 2100-Rigaku diffractometer (Rigaku Co., Tokyo, Japan). $\mathrm{CuK}_{\alpha}$ radiation and a fixed power source of $30 \mathrm{kV}$ and $20 \mathrm{~mA}$ were used. The X-ray diffraction patterns were obtained in the region of $2 \theta$ from $25^{\circ}$ to $75^{\circ}$, using a $0.02^{\circ}$ step size. The size of the crystallite was calculated using the Scherrer's equation [16].

$$
D=\frac{k \lambda}{\beta \cos \theta}
$$

where $D$ is the average crystallite size; $k$ is the Scherrer coefficient $(0.9) ; \lambda$ is the $X$-ray wave length

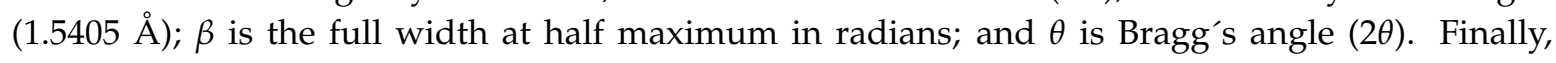
the morphology and size of the $\mathrm{ZnO}$ nanostructures was studied using the field emission scanning electron microscopy (FESEM) model JSM-7610F (JEOL, Tokyo, Japan). Microscopy analysis was performed at $10,000 \times$ and $100,000 \times$ with an accelerating voltage of $2 \mathrm{kV}$.

\subsection{Laboratory Experiments}

\subsubsection{Fungal Isolate}

The highly toxigenic strain of Aspergillus flavus Link (UNIGRAS-1231, Culture Collection of the Grain and Seed Research Unit of the National Autonomous University of Mexico) was grown in potato-dextrose-agar (PDA) medium for $7 \mathrm{~d}$ at $25{ }^{\circ} \mathrm{C}$. This fungus mainly produces $\mathrm{AFB}_{1}$ [17]. A sterile-water conidia suspension containing $0.5 \%$ Tween- 80 was prepared with approximately $4 \times 10^{6}$ spores $/ \mathrm{mL}$.

2.4.2. Effect of Nanostructured $\mathrm{ZnO}$ on the Growth of the Fungus and Aflatoxin Production in Liquid Media

For the experiment, $125 \mu \mathrm{L}$ of the conidia suspension (500,000 spores) were added to $250 \mathrm{~mL}$ round bottom flasks containing $100 \mathrm{~mL}$ of Sabouraud dextrose broth (SDB). Different concentrations of the $\mathrm{ZnO}$ nanostructures $(0.3125,0.625,1.25,2.5$, and $5 \mathrm{mM})$ were added to the flasks and cultures were incubated under agitation at $170 \mathrm{rpm}$ using an orbital shaker (PSU-10i, Boeco, Hamburg, Germany) for $3 \mathrm{~d}$ at $25^{\circ} \mathrm{C}$. At the end of the incubation period, the content of each flask was filtered through a Whatman no. 4 filter paper and subjected to $\mathrm{AFB}_{1}$ determination. The vegetative mycelium was used for dried weight estimation; the mycelium was dried at $70{ }^{\circ} \mathrm{C}$ for $72 \mathrm{~h}$, till their weights remains constant. For further detection on the effects of nanostructured $\mathrm{ZnO}$ on the fungus, scanning electron microscopy (SEM) was used. For this purpose, the mycelia was fixed for $3 \mathrm{~h}$ in $2.5 \%(\mathrm{v} / \mathrm{v})$ glutaraldehyde (100 mM phosphate buffer solution, $\mathrm{pH} 7.2)$, oven dried at $40{ }^{\circ} \mathrm{C}$ for $24 \mathrm{~h}$, and coated using a gold-sputter (Denton Vacuum Inc., Desk V HP, Moorestown, NJ, USA) for $5 \mathrm{~min}$. Microscopy analysis was performed using a SEM (JEOL, JSM-6012LA, Tokyo, Japan) at 500×, 1000 $\times$, and 5000 $\times$ with an accelerating voltage of $15 \mathrm{kV}$. 
2.4.3. Effect of Nanostructured $\mathrm{ZnO}$ on the Growth of the Fungus and Aflatoxin Production in Maize Grains

The nanostructured $\mathrm{ZnO}$ concentration that exhibited the strongest inhibitory activity in the liquid media experiment was further tested on maize grains. The fungal inoculation procedure was followed in accordance to the methodology suggested by Méndez-Albores et al. [18]. Regular maize of the commercial hybrid AS-900 (Aspros Comercial, Guanajuato, Mexico) grown and harvested in 2017 at Celaya-Guanajuato, Mexico, with 11.5\% moisture content (MC) was utilized. Experimental units containing $100 \mathrm{~g}$ of maize (five replicates of each treatment) were adjusted to $18 \% \mathrm{MC}$ and stored in $500 \mathrm{~mL}$ flasks resistant to steam sterilization. The water that was added to reach the desired MC served as a vehicle for the inoculum (5000 spores per gram of maize). To minimize the loss of MC from the maize grains, flasks were protected with polyethylene film. Ten perforations with a sterile pin were made to each film to prevent $\mathrm{CO}_{2}$ accumulation. Flasks were incubated at $27^{\circ} \mathrm{C}$ for 7 days. This short-term storage period was chosen, due to the highly favorable temperature and humidity conditions for the development of the toxigenic fungus in the maize grains. At the end of the incubation, experimental units were sterilized using ethylene oxide gas at a concentration of $1000 \mathrm{mg} / \mathrm{L}$ during $5 \mathrm{~h}$ [19]. Finally, the percentage of grains invaded by the fungus as well as the aflatoxin content was determined.

\subsubsection{Aflatoxin Assay}

Aflatoxin analysis was carried out following the recommendations of the 991.31 AOAC method [20], with immunoaffinity columns for $\mathrm{AFB}_{1}$ (VICAM, Milford, MA, USA). Samples (culture media or maize grains) were blended with $100 \mathrm{~mL}$ methanol-water $(80: 20 \mathrm{v} / \mathrm{v})$ and $5 \mathrm{~g}$ of $\mathrm{NaCl}$, and filtered through a Whatman no. 1 filter paper. Then, $10 \mathrm{~mL}$ of filtrate were diluted with $40 \mathrm{~mL}$ of deionized water, and the dilution filtered again with a micro-fiber filter. Subsequently, $10 \mathrm{~mL}$ of the diluted sample were passed through an immunoaffinity column (Aflatest-P; VICAM Science Technology, Watertown, MA, USA), which was then washed twice with $10 \mathrm{~mL}$ of deionized water. Aflatoxins were eluted from the immunoaffinity columns by passing $1 \mathrm{~mL}$ of methanol HPLC grade, and the toxins were collected in a fluorometer glass cuvette. Finally, $1 \mathrm{~mL}$ of $0.003 \%$ bromine solution was added to the elution and aflatoxins were quantified after 60 seconds in a fluorometer VICAM Series-4Ex (VICAM Source Scientific, Irvine, CA, USA). The limit of detection for aflatoxins using immunoaffinity columns is about $0.5 \mathrm{ng} / \mathrm{g}$.

\subsection{Statistical Analysis}

The experiment was carried out under a completely randomized design. The results were analyzed via analysis of variance (ANOVA) utilizing the Statistical Analysis System [21]. Mean values were separated with the Dunnett procedure using a significance value of $p<0.05$.

\section{Results and Discussion}

\subsection{Characterization of Nanostructured $\mathrm{ZnO}$}

\subsubsection{Optical Properties}

The UV-vis absorption spectrum of flower-shaped $\mathrm{ZnO}$ nanostructures is shown in Figure 1. The spectrum revealed the distinctive absorption peak $(3.25 \mathrm{eV})$, corresponding to the optical band gap of $\mathrm{ZnO}$, which is around $3.24 \mathrm{eV}$ [22]. The spectrum have two components: (1) the optical absorption due to electronic transitions in the nanostructured $\mathrm{ZnO}$, and (2) the dispersed light due to the scattering phenomenon, taken as absorbed light by the spectrophotometer [23]. 


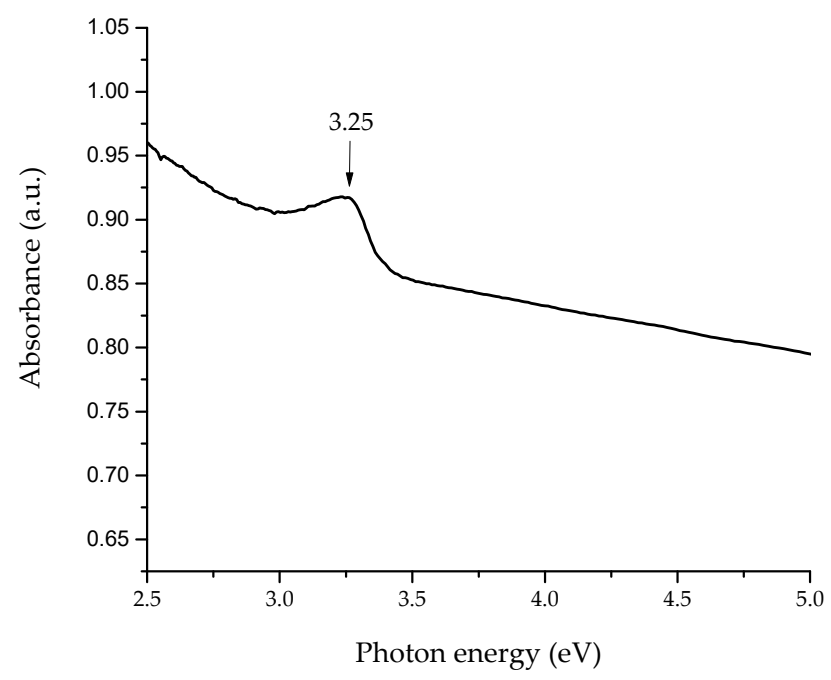

Figure 1. UV-vis absorption spectrum of synthesized flower-shaped zinc oxide (ZnO) nanostructures.

To avoid certain difficulties in obtaining the true optical band gap value of $\mathrm{ZnO}$ from UV-vis in dispersed samples, DRS measurements of powders were performed. As seen in Figure 2, the UV-vis spectrum showed a strong absorption edge at $400 \mathrm{~nm}$, related to the electron transitions from the valence band to the conduction band $\left(\mathrm{O}_{2 \mathrm{p}} \rightarrow \mathrm{Zn}_{3 \mathrm{~d}}\right)$. The DRS spectrum of the flower-shaped $\mathrm{ZnO}$ nanostructures after Kubelka-Munk treatment is shown in the inset of Figure 2. The intersection between the linear fit and the $x$ axis (photon energy) gives the optical band gap value. As a result, the direct band gap of the nanostructured $\mathrm{ZnO}$ was $3.17 \mathrm{eV}$. Yu et al. [24] reported a band gap value of $3.16 \mathrm{eV}$ for hexagonal phase $\mathrm{ZnO}$ rods with average diameter of $2 \mu \mathrm{m}$ and length of $7 \mu \mathrm{m}$. Compared with bulk $\mathrm{ZnO}(3.37 \mathrm{eV})$, the absorption edge of the flower-shaped $\mathrm{ZnO}$ nanostructures is red-shifted. This might be due to changes in morphology, particle size, and surface microstructures [25].

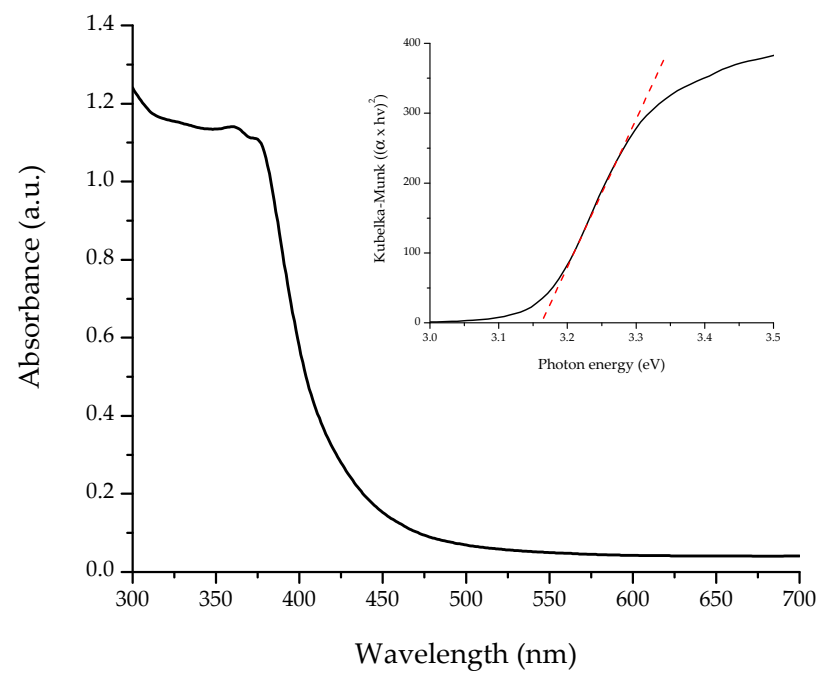

Figure 2. UV-vis diffuse reflectance spectrum of synthesized flower-shaped $\mathrm{ZnO}$ nanostructures. The inset shows their corresponding Kubelka-Munk transformed reflectance spectrum.

Fluorescence spectroscopy is often used to investigate certain optical properties of semiconductors. Figure 3 shows the fluorescence spectrum at room-temperature of the flower-shaped $\mathrm{ZnO}$ nanostructures with an excitation wavelength of $325 \mathrm{~nm}$. Five emission bands, including a strong ultraviolet emission at $401 \mathrm{~nm}(3.09 \mathrm{eV})$, were observed. Irimpan et al. [26] reported that the ultraviolet emission of $\mathrm{ZnO}$ has been related to the band gap fluorescence of clusters of different sizes [26]. 
In addition, the formation of $\mathrm{Zn}$ interstitials defects are associated with the blue emission at $423 \mathrm{~nm}$ $(2.93 \mathrm{eV})$, and the generation of oxygen vacancy defects are assigned to the blue emission at $445 \mathrm{~nm}$ $(2.79 \mathrm{eV})$ and blue-green emission at $485 \mathrm{~nm}(2.56 \mathrm{eV})$, respectively. Moreover, antisite defects originate the green fluorescence at $527 \mathrm{~nm}(2.35 \mathrm{eV})$ [15]. According to Vempati et al. [27], there are numerous energy levels due to defects such as zinc and oxygen vacancies and/or interstitials.

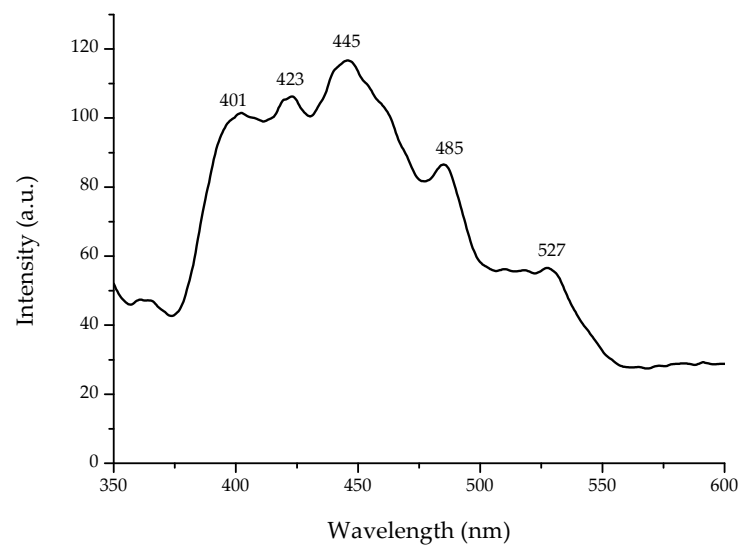

Figure 3. Room temperature fluorescence spectrum of synthesized flower-shaped $\mathrm{ZnO}$ nanostructures.

\subsubsection{FTIR Analysis}

The composition and quality of the flower-shaped $\mathrm{ZnO}$ nanostructures was analyzed by means of the FTIR-ATR spectroscopy technique. Figure 4 shows the spectrum, which was collected in the range of 350-4000 $\mathrm{cm}^{-1}$. Annealing in air atmosphere at $600{ }^{\circ} \mathrm{C}$ for $1 \mathrm{~h}$ significantly reduces the bands intensities in the region of $2800-3600 \mathrm{~cm}^{-1}$, due to the removal of water molecules and the convertion of $\mathrm{Zn}(\mathrm{OH})_{2}$ to $\mathrm{ZnO}$. In addition, the intensity of the impurities related FTIR signatures (1400-1600 $\left.\mathrm{cm}^{-1}\right)$ decreased significantly as a consequence of the decomposition of organic complexes. However, two significant bands were observed at $505 \mathrm{~cm}^{-1}$ and $373 \mathrm{~cm}^{-1}$ (Figure 4). While the band at $505 \mathrm{~cm}^{-1}$ corresponds to oxygen deficiency and/or oxygen vacancy defect complex in $\mathrm{ZnO}$ [28], the broad band at $373 \mathrm{~cm}^{-1}$ may be attributed to the $\mathrm{Zn}-\mathrm{O}$ stretching vibration mode [25].

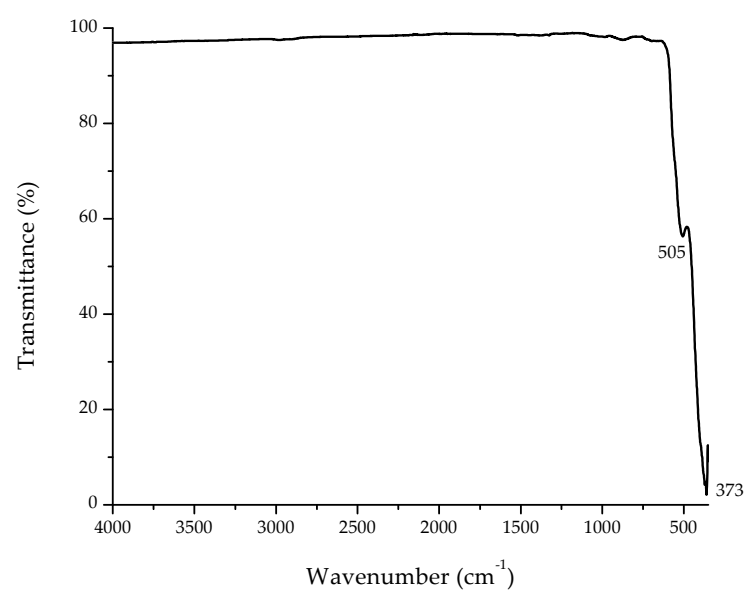

Figure 4. Fourier transform infrared spectroscopy with attenuated total reflection (FTIR-ATR) spectrum of synthesized flower-shaped $\mathrm{ZnO}$ nanostructures.

\subsubsection{X-ray Analysis}

XRD studies provide information about crystal structure, orientation, crystallite size, phase, and lattice parameters, among others. Figure 5 shows the XRD pattern of the synthesized ZnO 
nanostructures. All diffraction peaks for (1 $\left.\begin{array}{lll}1 & 0\end{array}\right),\left(\begin{array}{lll}0 & 0 & 2\end{array}\right),\left(\begin{array}{lll}1 & 0 & 1\end{array}\right),\left(\begin{array}{lll}1 & 0 & 2\end{array}\right),\left(\begin{array}{lll}1 & 1 & 0\end{array}\right),\left(\begin{array}{lll}1 & 0 & 3\end{array}\right),\left(\begin{array}{lll}2 & 0 & 0\end{array}\right),\left(\begin{array}{lll}1 & 1 & 2\end{array}\right)$, (2 01 1), and (0 04 4) planes are related to the formation of hexagonal (wurzite) structure of $\mathrm{ZnO}$, which is in accordance to the standard card JCPDS 36-1451. No other diffraction peaks from byproducts were observed.

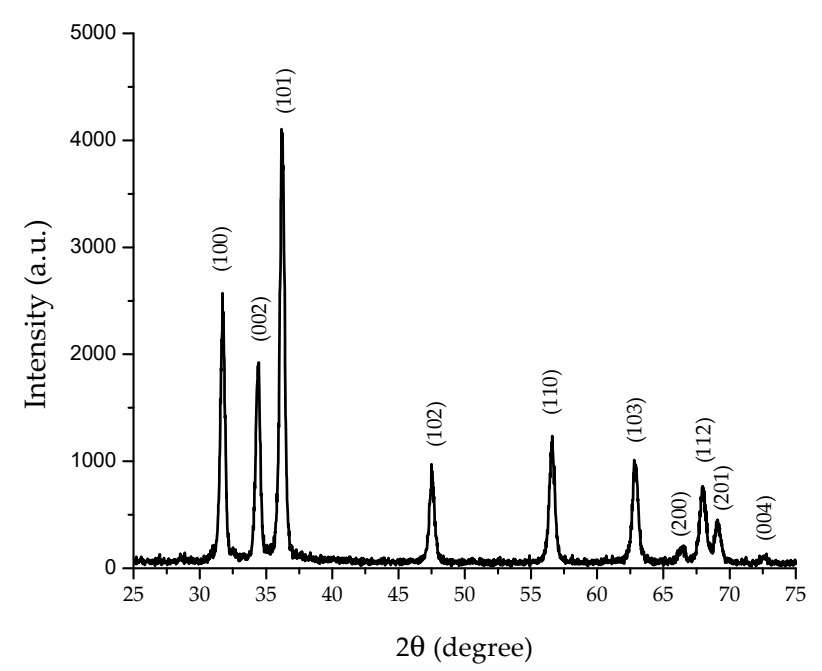

Figure 5. Representative X-ray diffraction pattern of synthesized flower-shaped ZnO nanostructures.

In addition, the broadening of the XRD peaks indicates that the crystallite size of the nanostructured $\mathrm{ZnO}$ is in the nanometer range. The crystallite size was determined using the Scherrer equation. The $\left(\begin{array}{lll}1 & 0 & 0\end{array}\right)$ plane was selected for calculation, and the average crystallite size was $42.0 \pm 0.8 \mathrm{~nm}$. The calculated lattice parameters were $\mathrm{a}=\mathrm{b}=3.254 \AA$, and $\mathrm{c}=5.207 \AA$ ( $\mathrm{c} / \mathrm{a}=1.6)$. Chand et al. [3] reported similar lattice constant values $(a=3.249 \AA$, and $c=5.207 \AA)$ for $\mathrm{ZnO}$ nanostructures synthetized at $\mathrm{pH} 12$, which is consistent with our findings.

\subsubsection{Morphology and Size of Nanostructured $\mathrm{ZnO}$}

Figure 6 shows the field emission scanning electron microscopy (FESEM) image of the nanostructured $\mathrm{ZnO}$. The image reveals that large-scale 3D flower-like $\mathrm{ZnO}$ is formed, and that most of the structures are in a uniform fashion, with diameters in the range of $700-800 \mathrm{~nm}$. The flower-shaped $\mathrm{ZnO}$ nanostructures are composed of structurally arranged flattened tipped hexagonal nanorods with diameters and lengths of around $120 \mathrm{~nm}$ and $280 \mathrm{~nm}$, respectively.

It can be seen that all hexagonal nanorods are joined together through their bases forming a flower-shaped morphology. It is well known that the shape and the size of the obtained $\mathrm{ZnO}$ depend strongly on the reaction conditions. In the literature, both precursors (zinc nitrate and potassium hydroxide) have been used to synthesize mainly spherical nanoparticles [29,30]. However, in this research, by using different reaction conditions, flower-shaped $\mathrm{ZnO}$ nanostructures were obtained. Besides, the reaction was carried out without the presence of surfactants. Li et al. [31] reported that star-like structures with 3, 4, 5, 6, or 7 branches, or flower-like particles with different numbers and shapes of leaves were synthesized at zinc acetate concentrations of $0.1 \mathrm{M}$ and above. 

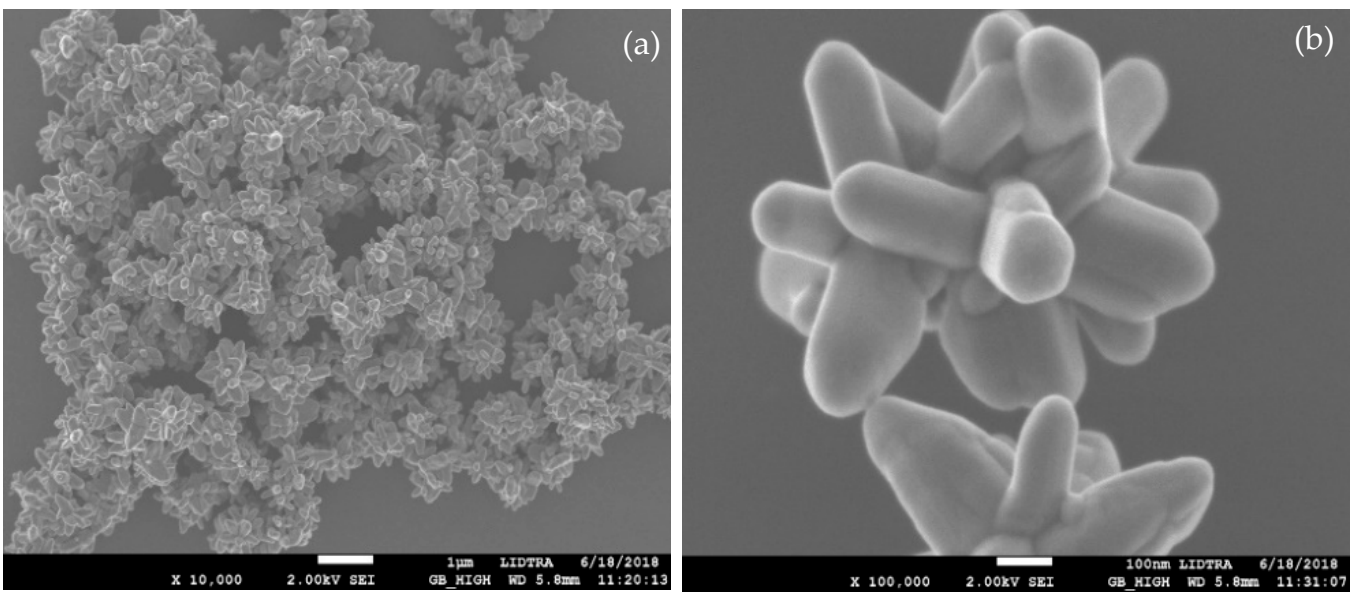

Figure 6. (a) Field emission scanning electron microscopy (FESEM) image of synthesized flower-shaped $\mathrm{ZnO}$ nanostructures; and (b) a high magnification image of a single flower.

\subsection{Antifungal and Anti-Aflatoxigenic Studies}

\subsubsection{Antifungal Activity (Liquid Media)}

Data indicate that nanostructured $\mathrm{ZnO}$ at a concentration of $0.3125 \mathrm{mM}$ showed no significant differences in mycelial dry weight, presenting average values similar to the control $(0.78 \mathrm{~g} / 100 \mathrm{~mL}$ culture media). It has been reported that low concentrations of solubilized $\mathrm{Zn}^{2+}$ can trigger a relatively high tolerance in microorganisms. However, a notable reduction in mycelial production of $A$. flavus was observed at concentrations of $1.25,2.5$, and $5 \mathrm{mM} \mathrm{ZnO}$, showing reductions up to $78 \%$ of the control level. $\mathrm{ZnO}$ at $0.625 \mathrm{mM}$ has the lowest reduction in mycelial growth, reaching values up to $51 \%$ (Figure 7).

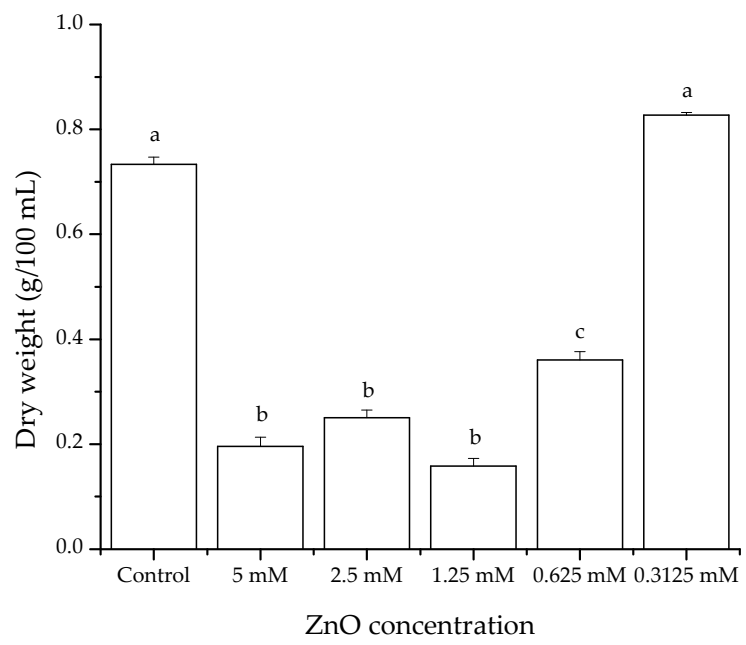

Figure 7. Effect of nanostructured $\mathrm{ZnO}$ on mycelial growth of Aspergillus flavus in culture media. Mean values \pm standard error of three independent experiments. Bars not sharing a common superscript differ significantly (Dunnett < 0.05).

Our results are in accordance to those of Jasim [32], who reported a reduced mycelial production $(60 \%)$ of the fungus A. fumigatus in culture media when using $6 \mathrm{mM}$ of $\mathrm{ZnO}$ nanoparticles $(<50 \mathrm{~nm})$. In another study in culture media, reductions up to $79 \%$ in mycelial production of $A$. flavus and A. parasiticus were reported using $0.325-1.5 \mathrm{mg} / \mathrm{mL}$ of Agave asperrima and Agave striata extracts [33]. Data are consistent with our findings. 


\subsubsection{Anti-Aflatoxigenic Activity (Liquid Media)}

Regarding aflatoxin biosynthesis, the mycotoxin content increased as the $\mathrm{ZnO}$ concentration decreased in the culture media (Figure 8). The aflatoxin content in the control was 11,133 ng/g. At concentrations of $1.25,2.5$, and $5 \mathrm{mM} \mathrm{ZnO}$, the aflatoxin content decreased $99.7 \%$, the average aflatoxin content in these experimental units was about $37 \mathrm{ng} / \mathrm{g}$. However, a $98.7 \%$ and $98.1 \%$ decrease was observed at $0.625 \mathrm{mM}$ and $0.3125 \mathrm{mM} \mathrm{ZnO}$, reaching aflatoxin values of $149 \mathrm{ng} / \mathrm{g}$ and $209 \mathrm{ng} / \mathrm{g}$, respectively. In this research, in just $3 \mathrm{~d}$, the $A$. flavus isolate was able to produce extremely high quantities of aflatoxins.

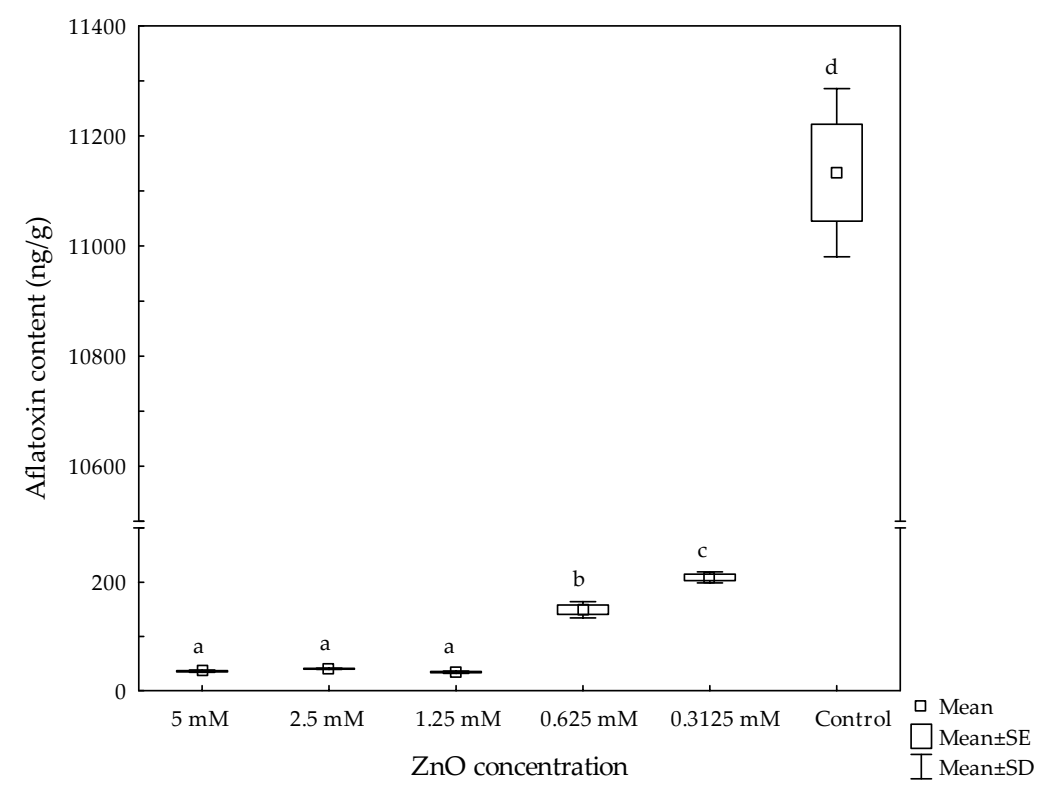

Figure 8. Effect of nanostructured $\mathrm{ZnO}$ on aflatoxin production in culture media. Boxes and whiskers not sharing a common superscript differ significantly (Dunnett $<0.05$ ).

When A. parasiticus PTCC5280 was inoculated $\left(10^{6}\right.$ conidia $\left./ \mathrm{mL}\right)$ to potato-dextrose broth (PDB) for $7 \mathrm{~d}$, an aflatoxin value of $70 \mathrm{ng} / \mathrm{g}$ was attained [34]. In the study, silver nanoparticles $(90 \mu \mathrm{g} / \mathrm{mL})$ completely inhibited the aflatoxin production. Furthermore, Al-Othman et al. [35] reported that five A. flavus isolates were inhibited to various extents by different concentrations of silver nanoparticles using SMKY liquid medium (sucrose, magnesium sulfate, potassium nitrate, and yeast extract). At a concentration of $150 \mu \mathrm{g} / \mathrm{mL}, 100 \%$ inhibition of aflatoxin production was reached. The aflatoxin values in control samples incubated during $20 \mathrm{~d}$ ranged from 18.6 to $69.3 \mathrm{ng} / \mathrm{g}$. In another study, Hassan et al. [11] found that $8 \mu \mathrm{g} / \mathrm{mL}$ of $\mathrm{ZnO}$ nanoparticles was an effective concentration to inhibit the production of aflatoxins by an A. flavus strain inoculated in YES (yeast extract and sucrose) broth for $20 \mathrm{~d}$. Control samples produced an aflatoxin content of $20 \mathrm{ng} / \mathrm{g}$. The inhibitory effect of $\mathrm{ZnO}$ on aflatoxin production varies considerably depending on several parameters, such as fungal isolate, spore load, culture media, incubation time, temperature, as well as the nanomaterial-type being evaluated.

\subsubsection{Structural Examination of the Fungus}

To determine the effect of $\mathrm{ZnO}$ on the growth of $A$. flavus and its ability to synthesize aflatoxins, SEM analysis was conducted evaluate the structural changes in the mycelium. SEM micrographs clearly indicate multiple degenerative alterations in morphology after treatment with $\mathrm{ZnO}$ at $1.25 \mathrm{mM}$ (Figure 9d-f), compared with the control group (Figure 9a-c). In general, untreated samples presented unicellular filaments with their typical structure with a smooth surface. However, after $\mathrm{ZnO}$ treatment, the tubular filaments showed damage such as deformation in mycelial growth, loss of hyphae shape 
and smoothness, as well as hyphae rupture. Cell membrane rupture probably results in reduction of the enzymatic activity of the fungus, leading to a significant reduction in mycelial dry weight and consequently, a possible interruption in the aflatoxin biosynthetic process.

It is well known that $\mathrm{ZnO}$ is moderately soluble and can release zinc ions $\left(\mathrm{Zn}^{2+}\right)$ in solution. There are two main approaches on the antifungal activity of $\mathrm{ZnO}$ : reactive oxygen species (ROS) generation and the release of $\mathrm{Zn}^{2+}$ in the medium. Released $\mathrm{Zn}^{2+}$ has significant effect in the amino acid metabolism and enzyme system disruption. Elevated intracellular $\mathrm{Zn}^{2+}$ also induced disruption of mitochondrial function [36,37], and triggered ROS generation [38]. Song et al. [39] evaluated the role of dissolved $\mathrm{Zn}^{2+}$ ions and ROS in the cytotoxicity of $\mathrm{ZnO}$ nanoparticles in the mouse macrophage Ana- 1 cells. Results showed that when the concentration of $\mathrm{ZnO}$ nanoparticles exceeded $40 \mathrm{\mu g} / \mathrm{mL}$, the dissolved $\mathrm{Zn}^{2+}$ concentration tended to equilibrium $(10 \mu \mathrm{g} / \mathrm{mL})$ in the complete cell medium. At concentrations of $\mathrm{ZnO}$ up to $100 \mu \mathrm{g} / \mathrm{mL}$, the dissolved $\mathrm{Zn}^{2+}$ concentration of fine $\mathrm{ZnO}, 100,30$, and 10-30 nm ZnO particles were 9.9, 9.7, 9.6, and $10.3 \mu \mathrm{g} / \mathrm{mL}$, respectively. Authors conclude that $\mathrm{Zn}^{2+}$ ions were responsible for the toxic effect of $\mathrm{ZnO}$ nanoparticles. ROS generation of nano- $\mathrm{ZnO}$ was not enough to cause cytotoxicity.

In this research, the antifungal and anti-aflatoxigenic effects of $\mathrm{ZnO}$ nanostructures were probably due to the release of $\mathrm{Zn}^{2+}$ ions into the SDB. Taking into account that the $\mathrm{pH}$ value of the broth was approximately 5.9, and according to the phase stability diagram for the $\mathrm{ZnO}(\mathrm{s})-\mathrm{H}_{2} \mathrm{O}[40,41]$, the soluble ionic form of $\mathrm{ZnO}$ is mainly $\mathrm{Zn}^{2+}$, which is predominant under slightly acidic conditions of $\mathrm{pH}<6.0$ [42].

\subsubsection{Fungal Invasion and Aflatoxin Production in Maize Grains}

The inoculated maize allowed the proliferation of A. flavus and the subsequent aflatoxin production. The aflatoxin production in maize was very low compared to liquid media. The results indicate that $\mathrm{ZnO}$ at $100 \mu \mathrm{g} / \mathrm{g}$ of maize was almost effective under the experimental conditions tested. As expected, the only fungus isolated was A. flavus, whose presence was abundant in the control grain, presenting a $67 \%$ fungal invasion. The high incidence of $A$. flavus agrees with the production of aflatoxins $(45 \mathrm{ng} / \mathrm{g}$ ). However, maize treated with $\mathrm{ZnO}$, presented a moderate fungal invasion $(30 \%)$, and a relatively low production of aflatoxins $(14 \mathrm{ng} / \mathrm{g})$. Such aflatoxin content was below the maximum tolerance $(20 \mathrm{ng} / \mathrm{g}$ ) permissible in Mexico for aflatoxin contamination in maize intended for human consumption [43]. Nabawy et al. [13] reported aflatoxin levels of $46 \mathrm{ng} / \mathrm{g}$ in yellow maize, and values of $12 \mathrm{ng} / \mathrm{g}$ in maize treated with $100 \mu \mathrm{g} / \mathrm{mL}$ spherical $\mathrm{ZnO}$ nanoparticles $(100 \mathrm{~nm})$. The experimental conditions tested were: A. flavus, isolates recovered from samples of animal feed; spore load, $10^{5}$ spores $/ \mathrm{mL}$; incubation temperature, $30^{\circ} \mathrm{C}$; incubation time, 1 month. To the best of our knowledge, the present study is the first one to demonstrate that 3D flower-like $\mathrm{ZnO}$ nanostructures-composed of 1D nanorods-possess significant antifungal and anti-aflatoxigenic activities against a highly toxigenic strain of Aspergillus flavus Link under in vitro and in situ conditions. 


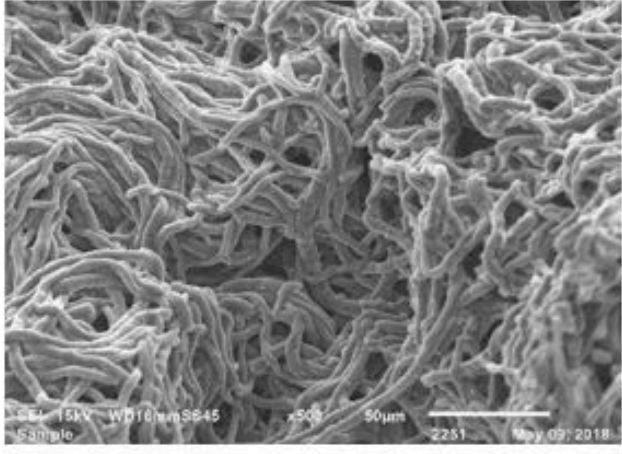

(a)

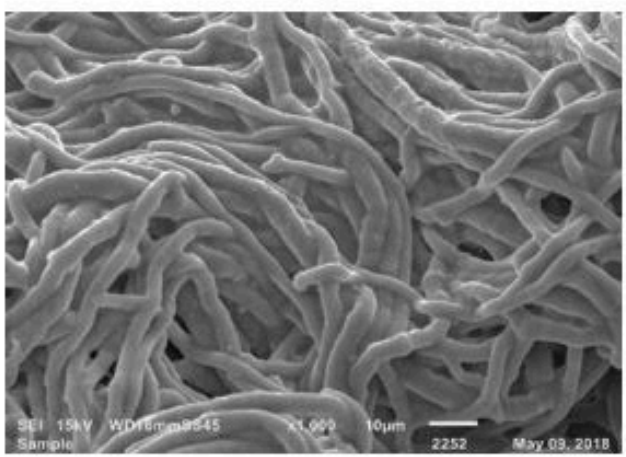

(b)

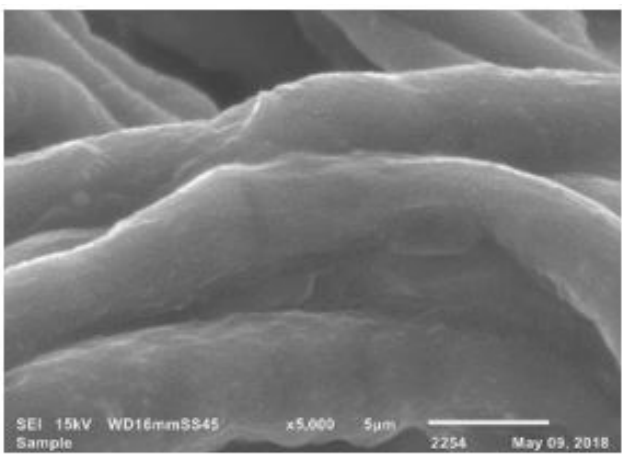

(c)

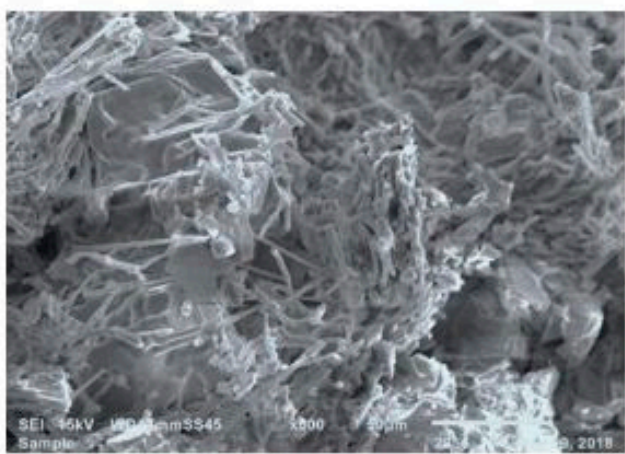

(d)

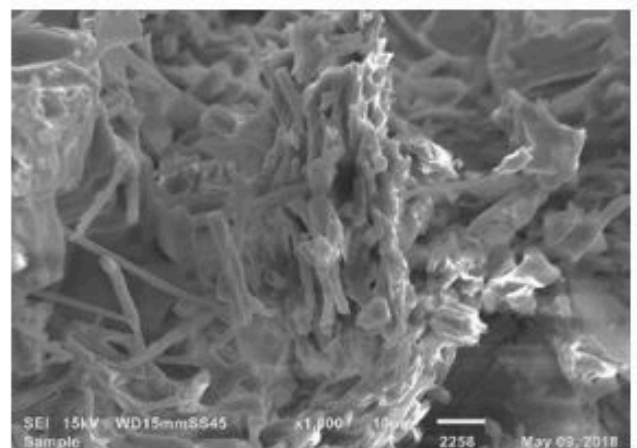

(e)

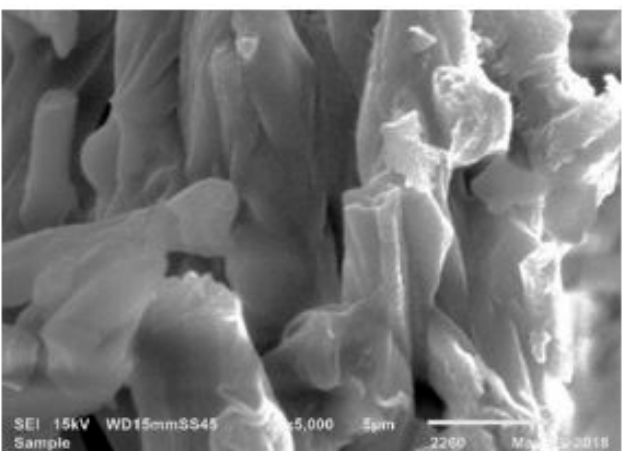

(f)

Figure 9. Scanning electron microscopy of Aspergillus flavus mycelium: (a-c) without treatment; (d-f) with nanostructured $\mathrm{ZnO}$ treatment at $1.25 \mathrm{mM}$. Profiles c,f are enlargements of b,e, respectively.

\section{Conclusions}

Flower-shaped $\mathrm{ZnO}$ nanostructures have significant antifungal and anti-aflatoxigenic activity against a highly toxigenic strain of Aspergillus flavus Link. $\mathrm{ZnO}$ nanostructures at a concentration of $1.25 \mathrm{mM}$ significantly inhibited the growth and aflatoxin production of the fungus in culture media. Furthermore, maize treated with $\mathrm{ZnO}(100 \mu \mathrm{g} / \mathrm{g}$ of maize), presented a moderate fungal invasion and a relatively low production of aflatoxins. Therefore, the application of $\mathrm{ZnO}$ nanostructures could be recommended as an effective fungicide against the major fungal pathogen of maize.

Author Contributions: A.V.-D. synthesized and characterized the nanostructures. D.H-M. and E.S.-T. carried out the in vitro and in situ trials and statistically analyzed the data. A.Z.-F. accomplished the aflatoxin analysis. G.T. took part in discussion and helped in editing the manuscript. A.V.-D. and A.M.-A. conceived and designed the experiment and wrote the paper. All authors read and approved the final version of the document.

Funding: This work was partially supported by Consejo Nacional de Ciencia y Tecnologia (CONACYT), research grant CB-220710. 
Acknowledgments: The authors wish to thank the expert technical assistance of Rivelino Flores Farías, José Eleazar Urbina Álvarez, and Martín Adelaido Hernández Landaverde from CINVESTAV-IPN in fluorescence, FESEM, and XRD analysis. A.Z.-F. acknowledges CONACYT for the PhD scholarship (286279).

Conflicts of Interest: The authors declare no conflict of interest.

\section{References}

1. Peng, Z.; Dai, G.; Chen, P.; Zhang, Q.; Wan, Q.; Zou, B. Synthesis, characterization and optical properties of star-like ZnO nanostructures. Mater. Lett. 2010, 64, 898-900. [CrossRef]

2. Ma, M.-G.; Zhu, Y.-J.; Cheng, G.-F.; Huang, Y.-H. Microwave synthesis and characterization of ZnO with various morphologies. Mater. Lett. 2008, 62, 507-510. [CrossRef]

3. Chand, P.; Gaur, A.; Kumar, A.; Gaur, U.K. Effect of $\mathrm{NaOH}$ molar concentration on optical and ferroelectric properties of ZnO nanostructures. Appl. Surf. Sci. 2015, 356, 438-446. [CrossRef]

4. Chaudhary, S.; Umar, A.; Bhasin, K.; Baskoutas, S. Chemical sensing applications of ZnO nanomaterials. Materials 2018, 11, 287. [CrossRef] [PubMed]

5. Servicio de Información Agroalimentaria y Pesquera (SIAP). Available online: https://www.gob.mx/siap (accessed on 7 June 2018).

6. Sargeant, K.; Sheridan, A.; O'kelly, J.; Carnaghan, R. Toxicity associated with certain samples of groundnuts. Nature 1961, 192, 1096-1097. [CrossRef]

7. Payne, G.A.; Widstrom, N.W. Aflatoxin in maize. Crit. Rev. Plant Sci. 1992, 10, 423-440. [CrossRef]

8. IARC. Some Naturally Occurring Substances: Food Items and Constituents, Heterocyclic Aromatic Amines and Mycotoxins. Available online: http://monographs.iarc.fr/ENG/Monographs/vol82/index.php (accessed on 7 June 2018).

9. Rodriguez-del-Bosque, L. Impact of agronomic factors on aflatoxin contamination in preharvest field corn in northeastern Mexico. Plant Dis. 1996, 80, 988-993. [CrossRef]

10. Ma, Z.; Michailides, T.J. Advances in understanding molecular mechanisms of fungicide resistance and molecular detection of resistant genotypes in phytopathogenic fungi. Crop Prot. 2005, 24, 853-863. [CrossRef]

11. Hassan, A.; Howayda, M.; Mahmoud, H. Effect of zinc oxide nanoparticles on the growth of mycotoxigenic mould. SCPT 2013, 1, 66-74.

12. Hassan, A.A.; Nahed, M.; El-Hamaky, A. Evaluation of the efficacy of Ozone fumigation and zinc oxide nanoparticles in control of aflatoxins contamination in cattle feeds. Anim. Health Res. J. 2017, 5, 165-180.

13. Nabawy, G.A.; Hassan, A.A.; Sayed El-Ahl, R.; Refai, M.K. Effect of metal nanoparticles in comparison with commercial antifungal feed additives on the growth of Aspergillus flavus and aflatoxin b1 production. J. Glob. Biosci. 2014, 3, 954-971.

14. Savi, G.D.; Bortoluzzi, A.J.; Scussel, V.M. Antifungal properties of Zinc-compounds against toxigenic fungi and mycotoxin. Int. J. Food Sci. Technol. 2013, 48, 1834-1840. [CrossRef]

15. Estrada-Urbina, J.; Cruz-Alonso, A.; Santander-González, M.; Méndez-Albores, A.; Vázquez-Durán, A. Nanoscale Zinc Oxide Particles for Improving the Physiological and Sanitary Quality of a Mexican Landrace of Red Maize. Nanomaterials 2018, 8, 247. [CrossRef] [PubMed]

16. Borchert, H.; Shevchenko, E.V.; Robert, A.; Mekis, I.; Kornowski, A.; Grübel, G.; Weller, H. Determination of nanocrystal sizes: A comparison of TEM, SAXS, and XRD studies of highly monodisperse CoPt $\mathrm{t}_{3}$ particles. Langmuir 2005, 21, 1931-1936. [CrossRef] [PubMed]

17. Jardon-Xicotencatl, S.; Díaz-Torres, R.; Marroquín-Cardona, A.; Villarreal-Barajas, T.; Méndez-Albores, A. Detoxification of aflatoxin-contaminated maize by neutral electrolyzed oxidizing water. Toxins 2015, 7, 4294-4314. [CrossRef] [PubMed]

18. Méndez-Albores, A.; Arambula-Villa, G.; Loarca-Piña, M.; Castano-Tostado, E.; Moreno-Martínez, E. Safety and efficacy evaluation of aqueous citric acid to degrade B-aflatoxins in maize. Food Chem. Toxicol. 2005, 43, 233-238. [CrossRef] [PubMed]

19. Pérez-Flores, G.; Moreno-Martínez, E.; Méndez-Albores, A. Effect of microwave heating during alkaline-cooking of aflatoxin contaminated maize. J. Food Sci. 2011, 76, T48-T52. [CrossRef] [PubMed]

20. Horwitz, W. Official Methods of Analysis of AOAC International; AOAC International: Gaithersburg, MD, USA, 2000.

21. SAS/STAT User's Guide. Version 8. Available online: http://www.okstate.edu/sas/v8/saspdf/stat/pdfidx. htm (accessed on 27 May 2018). 
22. Ashar, A.; Iqbal, M.; Bhatti, I.A.; Ahmad, M.Z.; Qureshi, K.; Nisar, J.; Bukhari, I.H. Synthesis, characterization and photocatalytic activity of $\mathrm{ZnO}$ flower and pseudo-sphere: Nonylphenol ethoxylate degradation under UV and solar irradiation. J. Alloys Compd. 2016, 678, 126-136. [CrossRef]

23. Morales, A.E.; Mora, E.S.; Pal, U. Use of diffuse reflectance spectroscopy for optical characterization of un-supported nanostructures. Rev. Mex. Fis. 2007, 53, 18-22.

24. Yu, J.; Li, C.; Liu, S. Effect of PSS on morphology and optical properties of ZnO. J. Colloid Interface Sci. 2008, 326, 433-438. [CrossRef] [PubMed]

25. Zak, A.K.; Abrishami, M.E.; Majid, W.A.; Yousefi, R.; Hosseini, S. Effects of annealing temperature on some structural and optical properties of $\mathrm{ZnO}$ nanoparticles prepared by a modified sol-gel combustion method. Ceram. Int. 2011, 37, 393-398. [CrossRef]

26. Irimpan, L.; Nampoori, V.P.N.; Radhakrishnan, P.; Deepthy, A.; Krishnan, B. Size dependent fluorescence spectroscopy of nanocolloids of ZnO. J. Appl. Phys. 2007, 102, 063524. [CrossRef]

27. Vempati, S.; Mitra, J.; Dawson, P. One-step synthesis of ZnO nanosheets: A blue-white fluorophore. Nanoscale Res. Lett. 2012, 7, 470. [CrossRef] [PubMed]

28. Muthukumaran, S.; Gopalakrishnan, R. Structural, FTIR and photoluminescence studies of Cu doped ZnO nanopowders by co-precipitation method. Opt. Mater. 2012, 34, 1946-1953. [CrossRef]

29. Sue, K.; Murata, K.; Kimura, K.; Arai, K. Continuous synthesis of zinc oxide nanoparticles in supercritical water. Green Chem. 2003, 5, 659-662. [CrossRef]

30. Ghorbani, H.R.; Mehr, F.P.; Pazoki, H.; Rahmani, B.M. Synthesis of ZnO nanoparticles by precipitation method. Orient. J. Chem. 2015, 31, 1219-1221. [CrossRef]

31. Li, S.; Gross, G.; Günther, P.; Köhler, J. Hydrothermal micro continuous-flow synthesis of spherical, cylinder-, flower-and flower-like ZnO microparticles. Chem. Eng. J. 2011, 167, 681-687. [CrossRef]

32. Jasim, N.O. Antifungal activity of Zinc oxide nanoparticles on Aspergillus fumigatus fungus \& Candida albicans yeast. J. Nat. Sci. Res. 2015, 5, 23-27.

33. Sánchez, E.; Heredia, N.; García, S. Inhibition of growth and mycotoxin production of Aspergillus flavus and Aspergillus parasiticus by extracts of Agave species. Int. J. Food Microbiol. 2005, 98, 271-279. [CrossRef] [PubMed]

34. Mousavi, S.A.A.; Pourtalebi, S. Inhibitory effects of silver nanoparticles on growth and aflatoxin B1 production by Aspergillus Parasiticus. Iran. J. Med. Sci. 2015, 40, 501.

35. Al-Othman, M.; El-Aziz, A.; Mahmoud, M.; Eifan, S.; El-Shikh, M.; Majrashi, M. Application of silver nanoparticles as antifungal and antiaflatoxin B1 produced by Aspergillus flavus. Dig. J. Nanomater. Biostruct. 2014, 9, 151-157.

36. Bishop, G.M.; Dringen, R.; Robinson, S.R. Zinc stimulates the production of toxic reactive oxygen species (ROS) and inhibits glutathione reductase in astrocytes. Free Radic. Biol. Med. 2007, 42, 1222-1230. [CrossRef] [PubMed]

37. Wiseman, D.A.; Wells, S.M.; Hubbard, M.; Welker, J.E.; Black, S.M. Alterations in zinc homeostasis underlie endothelial cell death induced by oxidative stress from acute exposure to hydrogen peroxide. Am. J. Physiol.-Lung Cell. Mol. Physiol. 2007, 292, L165-L177. [CrossRef] [PubMed]

38. Xia, T.; Kovochich, M.; Liong, M.; Mädler, L.; Gilbert, B.; Shi, H.; Yeh, J.I.; Zink, J.I.; Nel, A.E. Comparison of the mechanism of toxicity of zinc oxide and cerium oxide nanoparticles based on dissolution and oxidative stress properties. ACS Nano 2008, 2, 2121-2134. [CrossRef] [PubMed]

39. Song, W.; Zhang, J.; Guo, J.; Zhang, J.; Ding, F.; Li, L.; Sun, Z. Role of the dissolved zinc ion and reactive oxygen species in cytotoxicity of ZnO nanoparticles. Toxicol. Lett. 2010, 199, 389-397. [CrossRef] [PubMed]

40. Peterson, R.B.; Fields, C.L.; Gregg, B.A. Epitaxial chemical deposition of ZnO nanocolumns from $\mathrm{NaOH}$ solutions. Langmuir 2004, 20, 5114-5118. [CrossRef] [PubMed]

41. Zhang, Y.; Mu, J. Controllable synthesis of flower-and rod-like $\mathrm{ZnO}$ nanostructures by simply tuning the ratio of sodium hydroxide to zinc acetate. Nanotechnology 2007, 18, 075606. [CrossRef] [PubMed]

42. Reichle, R.A.; McCurdy, K.G.; Hepler, L.G. Zinc hydroxide: Solubility product and hydroxy-complex stability constants from $12.5-75^{\circ} \mathrm{C}$. Can. J. Chem. 1975, 53, 3841-3845. [CrossRef]

43. Norma Oficial Mexicana NOM-188-SSA1-2002. Productos y Servicios: Control de aflatoxinas en cereales para consumo humano y animal, especificaciones sanitarias. Diario Oficial de la Federacion 2002, 11.

(C) 2018 by the authors. Licensee MDPI, Basel, Switzerland. This article is an open access article distributed under the terms and conditions of the Creative Commons Attribution (CC BY) license (http:/ / creativecommons.org/licenses/by/4.0/). 